\title{
In memoriam Doz. Dr. Eva Sedláčková
}

Die Phoniatrische Sektion der tschechoslowakischen HNO-Gesellschaft wurde von einem grossen Verlust betroffen. Es verliess sie ihre Vorsitzende, Frau Doz. Dr. Eva Sedlácková CSc, Vorstand der Phoniatrischen Klinik und des Phoniatrischen Laboratoriums der Karls-Universität in Prag, gründendes Mitglied der Union der Europäischen Phoniater und ihre frühere Vorsitzende, Mitglied des Komitees der IALP und Mitglied des Internationalen Kollegiums fur experimen-tale Phonologie.

Die tschechoslowakische Phoniatrie verliert in Frau Doz. Dr. Eva Sedlácková CSc eine hervorragende pädagogische, wissenschaftliche und organisierende In memoriam Doz. Dr. Eva Sedlá ková

379

Persönlichkeit. Frau Doz. Dr. Eva Sedlácková CSc war das Vorbild eines über vollkommene Kenntnisse des Faches disponierenden HochschuUehrers. Dies ermöglichte ihr, den Lehrstoff in logisch gestalteter Form vorzutragen und eínen maximalen pädagogischen Effekt zu erzielen. Ihr wissenschaftliches Werk zählt über 80 Publikationen, von denen viele Weltpriorität erreichen. Frau Dozentin Sedlácková beschrieb als erste das Auftre-ten von Hörstörungen bei idiopathischer und symptomatischer Athetose. Ein Grossteil ihrer Arbeiten ist dem Studium der Sprachstörungen bei Kindern mit Gaumenspalte gewidmet. Als erste beschrieb sie die Insuffizienz des velopharyn-gealen Verschlusses bei Kindern mit der Entwicklungsstörung eines verkürzten Gaumensegels. Diese ätiologische Einheit trägt mit Recht ihren Namen als Syn-drom Sedlácková. Aus diesen Beobachtungen ging auch ihre originelle Ansicht über die doppelte Innervation des Gaumensegels hervor. Frau Dozentin Sedlácková klärte den Mechanismus der Entstehung der hyperkinetischen Dysphonie bei Kindern auf. Sie zog aus diesen Erkenntnissen Schlüsse für deren Behandlung und Prävention und arbeitete die Rehabilitationsmethoden bei professionellen Stimmstörungen aus. Von grosser Bedeutung sind ihre Arbeiten betreffend die Stimmstörungen bei Rekurrenslähmungen und deren Rehabilitation ebenso wie die Studie über Stimmstörungen bei endokrinen Erkrankungen. Die Physiologie und Pathologie der Stimme stand im Vordergrund ihres Inter-esses. Die Arbeiten, die dem Studium der Klanganalyse der Stimme von den ersten Schreien der Neugeborenen bis zum Zeitabschnitt der Reife gewidmet waren, wurden zur Grundlage von Dissertationsarbeiten. Die Monographie „Development of the Acoustic Pattern of the Voice and Speech in Newborn and Infant”, herausgegeben im Jahre 1967 vom Verlag CSAV (tschechoslowakische Akademie der Wissenschaften), ist ein umfassendes Werk hinsichtlich der subjek-tiven Beurteilung der Stimme sowie der objektiven akustischen Analyse. Es ist eine Arbeit, die eine Reihe origineller Konzeptionen enthält. Sie wurde mit dem internationalen „Gould Award” ausgezeichnet.

Die Untersuchungen der vegetativen Funktionen bei Sprachneurosen und das Konfrontieren dieser Ergebnisse mit den neuesten pharmakologischen Ergeb-nissen ermöglichten es, ein neues pharmakotherapeutisches Verfahren bei Sprachneurosen auszuarbeiten. 
Ihre letzten Arbeiten, die dem linguistischen und phonologischen Aspekt in der normalen sowie in der gestörten Sprache gewidmet sind, bringen die neuesten Konzeptionen und originelle Aspekte beim Studium von Sprachstörungen.

Die organisatorischen Bemühungen von Frau Dozentin Sedlácková reichten weit über die Grenzen der CSSR hinaus. Frau Dozentin Sedlácková half bei der In memoriam Doz. Dr. Eva Sedlácková

380

Organisation und dem Aufbau des phoniatrischen Faches in der DDR, in Polen, Ungarn und Rumänien. Während einer Reihe von Jahren schulte sie zahlreiche Kollegen aus diesen Ländern, sie half auch Kollegen aus anderen Staaten mit Rat und Tat.

Die Veranstaltung des II. Kongresses der Union der Europäischen Phoniater in Prag im Jahre 1973 wurde zum grossen Erfolg - persönlich und für die tschechoslowakische phoniatrische Schule.

Ihr Werk blieb unvollendet, es hat jedoch dauemden Wert als Quelle stän-diger Belehrung für alle Phoniater.

A. Novak

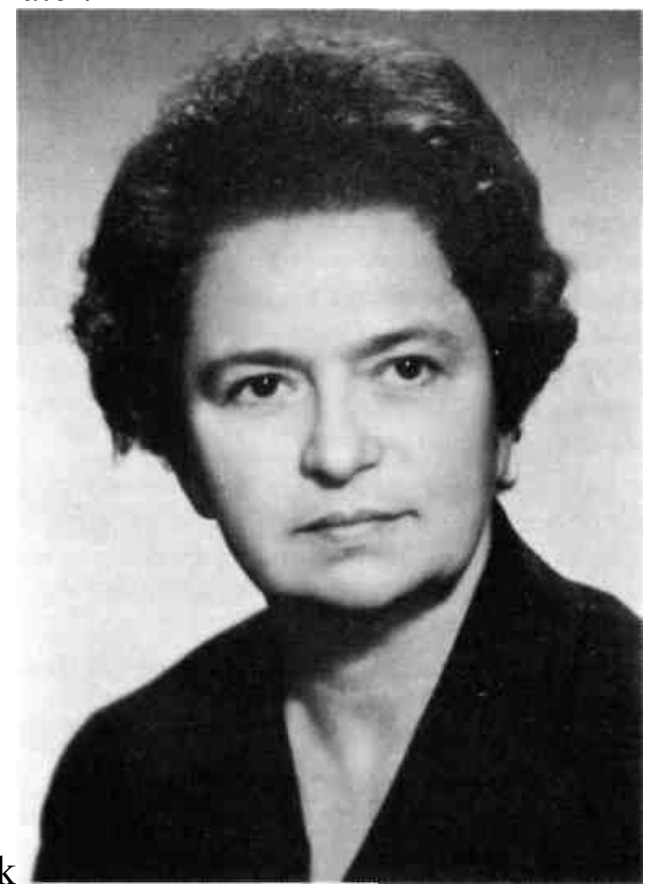

